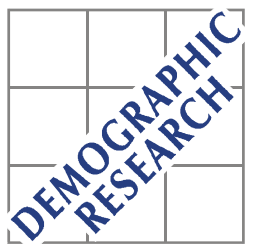

Demographic Research a free, expedited, online journal of peer-reviewed research and commentary in the population sciences published by the Max Planck Institute for Demographic Research Konrad-Zuse Str. 1, D-18057 Rostock · GERMANY www.demographic-research.org

DEMOGRAPHIC RESEARCH

SPECIAL COLLECTION 3, ARTICLE 1

PUBLISHED 17 APRIL 2004, PAGES 1-14

www.demographic-research.org/special/3/1/

DOI: 10.4054/DemRes.2004.S3.1

Reflexion

\title{
Contemporary Research on European Fertility: Introduction
}

\section{Gerda Neyer and Gunnar Andersson}

This special collection is in honor of Jan M. Hoem on his $65^{\text {th }}$ birthday. The authors presented their papers at a working party at the Max Planck Institute for Demographic Research in Rostock, Germany in April 2004. The collection is edited by Gunnar Andersson and Gerda Neyer.

(C) 2004 Max-Planck-Gesellschaft. 


\section{Table of Contents}

1 Fertility development and fertility research in 2

Europe

2 Contents of this special collection 4

3 Acknowledgments 11

$\begin{array}{ll}\text { References } & 12\end{array}$ 
Reflexion

\title{
Contemporary Research on European Fertility: Introduction
}

\author{
Gerda Neyer and Gunnar Andersson ${ }^{1}$
}

\begin{abstract}
This paper introduces a collection of related studies on different aspects of research on European fertility and family dynamics. The authors who have contributed to this special collection presented their papers at a working party at the Max Planck Institute for Demographic Research in Rostock, April 2004. This collection has been produced in honor of Jan M. Hoem for his $65^{\text {th }}$ birthday. It provides an overview of important approaches to, and relevant topics of European fertility research, as well as a number of case studies researching European fertility. In this introduction, we first give a brief summary of the present state of arts in fertility research in Europe, and we then proceed with an overview of the articles of the collection.
\end{abstract}

1 Max Planck Institute for Demographic Research, Konrad-Zuse-Straße 1, D-180 57 Rostock,

Germany. E-mail: neyer@demogr.mpg.de and andersson@demogr.mpg.de 


\section{Fertility development and fertility research in Europe}

Fertility and family behavior have gone through dramatic changes in Europe in recent decades. Total Fertility Rates (TFR) have declined to historical lows and are now below replacement level in virtually all European countries. In Western Europe, the fall of fertility has been accompanied by a progressive postponement of childbearing and first marriage, a trend that has also started to proliferate in Eastern Europe after the fall of state socialism. These developments have coincided with persistently large or even growing disparities among countries with regard to family and childbearing dynamics. Non-marital births, stepfamily childbearing, and premarital cohabitation have emerged as common modes of family formation in some countries. In others, marriage and marital births have remained the prevailing form of transition to adulthood and to parenthood. As a consequence, whilst overall fertility (as measured by the TFR) has converged, patterns of childbearing behavior and family dynamics in Europe have become more diverse.

These developments have opened up exciting new perspectives for European fertility research. Below we discuss the following three dimensions: topics, approaches, and methodologies. First, the changing patterns of population and family dynamics and the emergence of different trends in childbearing behavior and family arrangements across Europe raise new topics in demographic research, involving the state, the trajectories, and the causes of fertility development. Why is there such diversity in patterns and trends of fertility and family formation in Europe? How and to what extent is the demographic diversity of Europe interlocked with its cultural, institutional, and economic diversity? What accounts for the fact that despite national differentials in demographic patterns we also find cross-national similarities that indicate the existence of distinct "demographic regimes" in Europe? Are these demographic regimes intertwined with European welfare regimes? What role do national policies, citizenship, social rights, and policy changes play in the emergence of new forms of reproductive behavior or the perseverance of specific modes of family formation? What impacts have different economic systems and policy configurations on women's and men's social and economic position? How does this influence their life-course decisions and their childbearing behavior? What effects have new forms of family formation, such as childbearing in consecutive unions or the postponement of the transition to parenthood, for overall fertility development and fertility levels in Europe?

Secondly, to seek answers to these and similar questions, researchers have started to broaden the conventional theoretical and empirical approaches to fertility research. Mainstream demographic research usually attributes changes in fertility and family behavior to economic and cultural factors. These factors are important components of fertility and family change. Yet, demographers have also pointed out that we need to 
expand the theoretical and explanatory basis beyond these "classical" dimensions and include other factors, such as psychological, institutional, or political factors in fertility research. To recognize such factors seems particularly promising in the case of Europe, with its highly developed and diversified systems of welfare states, its different forms of capitalism, its past history of planned economies and state socialism, and its cultural and social heterogeneity. A proper acknowledgment of the potential influence of multiple factors poses a challenge to theoretical assumptions that tie individual childbearing decisions solely to economic and cultural rationales. Despite some promising attempts, we still lack insight into how psychological, cultural, social, economic, and institutional factors are interrelated with each other and how each of these factors and the interaction among them affect individuals and their demographic behavior. The diversity of Europe provides an incentive to further develop research approaches that consider such factors and to seek multi-faceted explanations of childbearing behavior and family formation (Hoem et al. 2000, Neyer 2003).

Third, to investigate European fertility, we need to incorporate theoretical insights and methodological approaches from various disciplines, such as sociology, anthropology, psychology, political science, economics, or feminist research. Each of these disciplines has developed different ways of investigating and explaining behavior and assessing factors that influence it. A better integration of these methodologies in demographic research might illuminate further aspects of childbearing behavior and family formation that have so far gone unnoticed or remained unexplained.

In recent years, as comparable data for a wider range of countries have become available (Andersson and Philipov 2002 provides one example), European demographers have increasingly turned to comparative research of family dynamics. Cross-country studies have not only confirmed and further underlined the great heterogeneity of demographic behavior in Europe, but have also shed light on national idiosyncrasies of fertility and family dynamics. Viewing the results of investigations for one country in the context of others allows us to better assess what factors may have contributed to generating the country-specific patterns of behavior.

To understand demographic trajectories and the impact of different factors on individual behavior, we clearly need to resort to longitudinal, individual-level data and apply event-history analyses to such data. This allows us to study demographic processes as they evolve over time, occurring parallel to and interdependent with other processes. Studies based on such stringent empirical methods are better able to reveal the impact that different micro- and macro-level factors have on family formation and childbearing behavior.

In summarizing, we find that the diversity of European fertility development opens up new directions for fertility research, with a broad range of new topics and approaches. It calls for the development of rigorous empirical models and the 
application of advanced methods to sort out the competing factors that influence fertility and family formation in Europe.

To enhance such a "new demography of Europe" has been at the core of the Research Programme on Contemporary European Fertility and Family Dynamics at the Max Planck Institute for Demographic Research under the leadership of Jan Hoem. From the onset he promoted research lines that were truly interdisciplinary and international, bringing together researchers from a variety of disciplines and countries. Convinced that deeper insights into the complexities of the demographic life-course can only be obtained through the application of advanced statistical methods, he has encouraged scholars to venture into these methodologies and trained a generation of demographers from all over Europe in event-history methods. These scholars have subsequently begun to break new grounds in fertility research by investigating childbearing behavior and family formation from disparate angles and in different countries.

The various contributions of this special volume of Demographic Research present a range of these new directions. They might serve nicely as a starting point for anyone who wishes to enter the field of European fertility research. The contributions provide a good picture of the state of affairs of such research by giving a number of examples of the most relevant approaches to fertility dynamics in Europe. From a methodological point of view, the volume provides several instructive cases of competently performed empirical studies of childbearing processes in Western and Eastern Europe.

\section{Contents of this special collection}

The present volume assembles a series of articles that illustrate this "new demography of Europe". It demonstrates that studying the demographic changes in Europe affects all dimensions of research, prompting re-directions in topics, methods, research design, and interpretation. The collection starts with a number of articles that deal with different perspectives of fertility research. They present relevant approaches to childbearing behavior and family formation in Europe and demonstrate the insight we gain from considering multiple explanatory factors. This is followed by contributions that address new topics that arise with changing population and family dynamics in Europe, discuss methodological issues that occur if we want to use adequate methods but have only insufficient data, and illustrate the potential that lies in comparative research for the understanding of demographic change in individual countries. The final part of the volume serves to illustrate how the challenges of recent fertility development in Europe can be tackled in empirical life-course research. Focusing on the Nordic countries and 
on East Central Europe these articles furthermore demonstrate that many common theoretical assumptions about childbearing behavior need to be reconsidered.

The cultural, political, economic, and demographic diversity of Europe, both historical and contemporary, has always been a challenge for researchers. In seeking comprehensive explanations of childbearing behavior and fertility differentials in Europe, demographers are confronted with the question to what extent different factors may be held accountable for the diverse developments of fertility and family formation. Francesco Billari addresses this issue, taking the extreme cases of "earliest-early" and "latest-late" transition to adulthood in Europe as an example to discuss two explanatory directions, the role of macro-level factors and trends, on the one hand, and the interaction between macro- and micro-level factors, on the other hand. Looking for macro-level explanations of the diverse transition to adulthood in Europe, Billari argues that both long-term institutional and cultural trends, such as the welfare state or the cultural history in Europe, as well as short-term trends, such as policies and ideational changes, provide explanation for the current patterning. He arrives at a similar conclusion regarding the interactions of micro-macro and macro-macro factors and its impact on demographic behavior. As a consequence, Billari calls for a demography that pursues multifaceted approaches, and includes historical, economic, cultural, and institutional factors in its search for explanations of the demographic diversity of Europe.

The changes in the demographic landscape of Europe, the diversification of family formation and childbearing patterns, with prolonged single living, pre-marital cohabitation, consecutive union formation, non-marital childbirth in cohabiting unions, and postponement of marriage and parenthood, have been accompanied by fundamental changes in value orientation towards accentuation of individual autonomy in ethical, moral, and political matters, and the rejection of institutional control and authority. The connection between demographic and values transformation forms the core of "Europe's Second Demographic Transition" (Lesthaeghe and van de Kaa 1986, van de Kaa 1987). In their contribution to this volume, Johan Surkyn and Ron Lesthaeghe investigate to what extent the association between patterns of value differentiation and household diversification can be found in Northern, Southern, and Western Europe. Using the European Value Survey of 1999, they show that in all these regions there is a clear statistical association between a variety of values orientation and family types, and that this association persists after controlling for various variables. Differences among the regions can often be attributed to the different historical developments regarding culture, family, and social organization. The results of the study by Surkyn and Lesthaeghe underline the need to look at the connection between ideational transformation, event-based adaptation of values, and demographic changes to understand the demographic trends in Europe. 
One of the most remarkable recent population changes in Europe has been the rise in immigration to the countries of the European Union. Over the past two decades all Western European countries, including those that historically have been senders of migrants, have turned into immigration areas. Drawing on contemporary anthropology, Caroline Bledsoe investigates the changes in the meaning of reproduction in the context of international migration. She shows that fertility and children might acquire new values as they can offer legitimacy to families in their efforts to get access to rights of residency, work, or social security. Bledsoe argues that since for some immigrant groups reproduction is a vital element in attaining political legitimacy, childbearing behavior of immigrants is unlikely to adjust to national norms unless their status are more secure.

In recent decades Europe has seen a marked increase in divorce, re-marriage, and non-marital childbearing. Between 8 and $28 \%$ of marriages in Europe end in divorce within 15 years from marriage formation; between 9 and $46 \%$ of children in Europe live for some time during their childhood and youth in a one-parent family (Andersson 2002a,b). These changes have resulted in an increased prevalence of stepfamilies in Europe (Prskawetz et al. 2003). Elizabeth Thomson shows that in many European countries stepfamily fertility comprises a substantial proportion of third and higherorder births. Childbearing in consecutive unions has thus become a critical component of overall fertility. Investigating prospective childbearing desires of couples in various European countries, she illustrates the unique value that at least one shared child represents for a couple, even if one or both partners already have two or more children from a previous union. Thomson concludes that as stepfamilies become more prevalent in Europe, the values of a shared child expressing the couple's commitment and creating a "real family" may be a key to maintaining fertility at moderate levels in lowfertility societies.

Research of stepfamily childbearing behavior requires data that allow us to reconstruct union and childbearing histories on the individual level. Demographers have long been aware of such a need and of the need to investigate demographic events over the life-course, using longitudinal individual-level data and applying event-history techniques. Such an approach offers the possibility to gain deeper insights into the effects that different factors have on childbearing behavior. In order to exploit the potentials of event-history analyses, we need data that do not only contain information about certain demographic events that occur at specific points in time, but we need data that provide complete histories of event-episodes as they occur over a person's lifecourse, such as childbearing histories, partnership histories, employment histories, unemployment histories, education histories, and so forth. Unfortunately, data that contain complete life histories are often not available. Scholars who start venturing into event-history analysis are thus often tempted to use a variable that provides information 
about a later point in time than the time segment studied. For example, they might consider using educational attainment at time of interview when studying a woman's previous childbearing behavior. However, this educational level might be different from the one she had obtained at the time of being at risk of having a child and, moreover, the birth - or non-birth - of any child might even have induced her to attain the educational level she reports at the time of interview. Every student (including most of the authors of this special volume), who has ever participated in Jan Hoem's eventhistory courses, probably remembers one of his most strongly repeated statements regarding such an attempt: "This is 'anticipatory analysis' and we should steer clear of it". Øystein Kravdal, who inspired us to report Jan's advice against anticipatory analysis, takes this as a starting point to illustrate the importance of Jan's warnings. He uses Norwegian register data to estimate the effects of education on births, using a parity-specific approach and different representations of education. The register data provide complete birth histories of women and other valuable information, but they only contain education histories for some years and not for others. Kravdal demonstrates that an anticipatory analysis, here in the form of the inclusion of educational level at a woman's latest observed age rather than at any current age, can produce substantially biased education effect estimates. He furthermore illustrates that imputations of education for earlier years may also lead to wrong conclusions. He concludes that we should not only follow Jan Hoem's advice and refrain from using later information to analyze earlier events in hazard-regression models, but he also calls for the inclusion of proper educational and other histories in future demographic surveys.

The population-register data of the Nordic countries provide a rich source to study fertility development over time and social groups, as well as across countries with modern event-history techniques. Demographers and social scientists have long been puzzled by the pattern of childbearing in the Nordic countries: Sweden, Norway, Denmark, and Finland. These countries combine relatively high fertility with high female labor-force participation. Moreover, contrary to many other European countries, fertility in these countries seems to have recuperated. Despite many common features in the fertility developments of the Nordic countries, there are also some country-specific differences. Using the Total Fertility Rate as a comparative measure we find that fertility developments have been quite stable in Finland and Norway in recent decades, but undulating greatly in Sweden. Yet, the TFR is too crude a measure to provide accurate information about the childbearing behavior that produces it. As Jan Hoem (1991, 1993a) suggested we need measures that display disaggregated trends of childbearing of subgroups of women, control for compositional changes over these subgroups, and capture the changes in the propensity to give birth. Gunnar Andersson uses such an event-history approach to investigate whether the Scandinavian countries 
represent a "Nordic demographic regime", or whether the differences in childbearing trends among them do not allow for such a clustering. Comparing parity-specific childbearing patterns calculated from register data, Andersson maintains that despite country-specific differences, fertility trends in the Scandinavian countries impress through their similarities. There are indications that some differences in childbearing behavior in the various countries are due to differences in public policies directed at childbearing women. Such policy impacts are often difficult to verify. But as Andersson shows with respect to Norway, a comparative approach may offer the possibility to detect potential policy impacts that might not be noticed in a single-country study. $\mathrm{He}$ furthermore shows that comparative research allows us to verify results from singlecountry studies and thus enables us to better assess the factors that have induced changes in childbearing behavior. As a consequence, his comparison of childbearing behavior in the Scandinavian countries confirms that the distinct changes in birth spacing in Sweden in the 1980s were indeed engendered by the introduction of a "speed premium", as first demonstrated by Jan Hoem (1990, 1993b). Andersson's comparison also shows that the highly volatile childbearing trends in Sweden are indeed particular to this country. Earlier research finds that to some extent, this pattern can probably, be attributed to special features in this country's welfare policies, in particular the close link between the level of parental-leave benefits and previous employment, and to economic factors (Andersson 2000). Both of these elements instigated a "pro-cyclical" fertility behavior in the 1980s and 1990s, reflected in the Swedish pattern of a "rollercoaster fertility" (Hoem and Hoem 1996) during this period.

The assumption that welfare-state policies and economic development need to be taken into account when investigating fertility trends is corroborated by Andres Vikat's analysis of the relationship between women's labor-force participation, fertility, and public policies in Finland since the late 1980s. Vikat finds that a woman's economic activity and income increase her propensity of entering motherhood and, to a lesser extent, of having a second child. This corresponds to the patterns of childbearing behavior found in other Nordic countries and supports the notion that there exists a common Nordic pattern of a (positive) relationship between female employment, women's earnings, and fertility. However, contrary to Sweden, childbearing patterns in Finland did not display a discernable fluctuation with economic cycles. Vikat provides two explanations for this. First, contrary to Sweden, the depressing macro-level impact of the economic recession of the early 1990s on fertility appears to have been relatively weak in Finland. During the recession years, people in Finland seem to have remained confident about their long-term prospects. Second, the existence of the Finnish "homecare allowance", which offers women the possibility to take extended childcare leave and receive an allowance if their under-three year old child does not use public childcare, may have reduced the economic effects of unemployment and thus reduced 
the impact of the recession on childbearing behavior. Vikat argues that although the take-up of home-care allowance did not increase childbearing risks (except for third birth), it may have induced some women to refrain from employment at a time when the possibilities for career advancement or re-entry into the labor-market after childbearing were low. His study thus demonstrates the need to combine various explanatory factors in order to gain insight into fertility behavior.

In the concluding contributions of this special volume, we turn to fertility developments in East Central Europe before and after the fall of communism to further illustrate the challenge and the opportunity that the diversity of Europe presents to demographic research. The Eastern European countries during state socialism have often been regarded as constituting a demographic regime of their own. Compared to Western Europe, fertility was fairly high, women's mean age at first and subsequent births was low, as was the level of childlessness. Marriage was nearly universal and couples usually married at young ages. Such patterns of family formation and childbearing were largely generated by the social organization of work and the comprehensive support of women's employment and family welfare in the Eastern European countries. Investigating childbearing in state-socialist Hungary, Poland, the Czech Republic, and the German Democratic Republic, Livia Oláh and Ewa Fratczak, Vladimira Kantorová, and Michaela Kreyenfeld show that the patterns of childbearing behavior in the former Eastern European countries were indeed rather homogenous. Cross-country differences in women's transition to motherhood were rather small and often pertained to select groups of women. Although differences in the state support for mothers accounted for some cross-country differences in women's propensity to have a first child, they did not affect the general fertility patterns significantly. Comparing childbearing behavior of women in a co-residential union in state-socialist Hungary and Poland, Oláh and Fratczak nevertheless find a number of differences in how a woman's employment status and educational attainment affected her entry into motherhood in the two countries. One finding is that highly educated women often tended to postpone any first birth, and that this pattern appeared stronger in Poland than in Hungary. Oláh and Fratczak attribute these patterns to differences in the state support for mothers in Hungary and Poland. They argue that although in both countries maternal policies facilitated the combination of employment and family responsibility for all women and thus contributed to gender equality on the employment level, policies failed to contribute to changes in gender relations on the family level.

Kantorova investigates the role of education in the transition to motherhood in the Czech Republic before and after 1990. She also stresses the importance of the institutional setting and of public policies on fertility behavior. Like in other Eastern European countries education differentiation had generally only a small impact on firstbirth risks in the Czech Republic during state socialism. Kantorová ascribes this not 
only to population policies that ensured the reconciliation of childrearing with women's employment, but also to the state-regulated employment system. State-guaranteed working contracts and centrally determined wages with relatively narrow wage gaps reduced the economic returns of education. With the transition to a market economy and to a family-policy system that rather supports mother's withdrawal from the labor market, education became a source of economic opportunity and constraint. This resulted in a significant postponement of first birth and a decline in first-birth fertility of highly educated women. Comparing two institutional settings with different economic evaluation of women's education, Kantorová concludes that the effect of women's education on the timing of first births seems to be mainly influenced by the way in which women's education is rated on the labor market.

Kreyenfeld, who compares family policies and fertility patterns in the former German Democratic Republic (GDR) and the Federal Republic of Germany (FRG), puts forth similar arguments regarding the connection between women's education, their employment, and fertility. The two Germanies provide a particularly intriguing example of the pervasive role of institutional factors in the social structuring of childbearing. For example, both states pursued contrasting policies regarding women's employment. The GDR geared its family and employment policies towards ensuring women's full-time employment; the FRG promoted mothers' withdrawal from the labor market. Kreyenfeld shows that these differences led to very different childbearing behavior and different first-birth patterns in the two Germanies. In East Germany, women of all educational groups initiated childbearing shortly after the end of their education and their entry into employment. As a consequence, childlessness in the GDR was very low in all educational groups. In West Germany, particularly highly educated women postponed parenthood until several years after labor-market entry, or to a very large extent refrained from having a child at all.

Summarizing their results, Oláh and Fratczak, Kantorová, and Kreyenfeld all take issue with economic theories that tie fertility decline and differences in childbearing behavior among women with different educational attainment to the incompatibility of childrearing and employment. As in the case of the Nordic countries, their investigations demonstrate that an institutional setting that eases the tension between employment and childrearing may also mitigate fertility differentials and fertility decline. However, their research also indicates that family policies that focus on childrearing alone may not suffice. Public policies also need to impinge on the labor market and reduce the negative employment consequences connected to women's potential or factual childbearing and childrearing. Viewed from this perspective, the research on childbearing in state-socialist countries also challenges theoretical assumptions that usually imagine markets as free and unstructured. Although the planned economies of the former Eastern European countries provide an extreme case 
of regulated markets, the connection between these structured markets and fertility behavior indicates that demographic research needs to pay more attention to the specificities of the environment in which women and men live and work.

This brings us back to the research perspectives that Jan Hoem has envisaged for a demography of Europe and promoted as a demographer: "To provide a better understanding of differences in levels, trends, and patterns of fertility in Europe, and to contribute to the advancement of demography, we need to critically assess our theoretical assumptions, cross disciplinary borders and search for better explanations by testing our assumptions with the proper statistical and empirical methods." The articles in this volume provide examples of what this "new demography of Europe" could be.

\section{Acknowledgments}

This special collection of Demographic Research has been produced as a birthday present for Jan Hoem. On behalf of all the authors of the volume we would like to wish Jan a Happy Birthday. We are grateful for having had the opportunity to be part of the dynamic research environment that he has stimulated, and we wish to express our appreciation for his constructive, encouraging, and unselfish attitude in regards to demographic research. In short, Jan is a very good guy, and the fact that we have managed to gather such an excellent crowd of authors for this special collection shows that there are many of us who share these feelings. We want to thank all the authors for their very professional and competent collaboration in creating this special volume. Finally, we wish to thank Renée Flibotte as the Acting Managing Editor of Demographic Research for having very competently ensured that we really managed to complete the project. 


\section{References}

Andersson, G., 2000. "The impact of labor-force participation on childbearing behavior: Pro-cyclical fertility in Sweden during the 1980s and the 1990s." European Journal of Population 16: 293-333.

Andersson, G., 2002a. "Dissolution of unions in Europe: A comparative overview." Zeitschrift für Bevölkerungswissenschaft 27: 493-504. Also available as MPIDR Working Paper 2003-04. Max Planck Institute for Demographic Research, Rostock.

Andersson, G., 2002b. "Children's experience of family disruption and family formation: Evidence from 16 FFS countries." Demographic Research 7: 343364. Available http://www.demographic-research.org/Volumes/Vol7/7.

Andersson, G., and Philipov, D., 2002. "Life-table representations of family dynamics in Sweden, Hungary, and 14 other FFS countries: A project of descriptions of demographic behavior." Demographic Research 7: 67-270. Available http://www.demographic-research.org/Volumes/Vol7/4.

Hoem, B., and Hoem, J.M., 1996. "Sweden's family policies and roller-coaster fertility." Jinko Mondai Kenkyu (Journal of Population Problems) 52: 1-22.

Hoem, J.M., 1990. "Social policy and recent fertility change in Sweden." Population and Development Review 16: 735-748.

Hoem, J.M., 1991. "La standardisation indirecte améliorée et son application à la divortialité en Suède (1971-1989)." Population 46: 1551-1568.

Hoem, J.M., 1993a. "Classical demographic methods of analysis and modern eventhistory techniques." IUSSP: $22^{\text {nd }}$ International Population Conference, Montreal, Canada, Volume 3: 281-291.

Hoem, J.M., 1993b. "Public policy as the fuel of fertility: effects of a policy reform on the pace of childbearing in Sweden in the 1980s." Acta Sociologica 36: 19-31.

Hoem, J.M. et al., 2000. "The ECE/PAU Generations and Gender Programme: Concepts for a second round of Fertility and Family Surveys in Europe, with particular attention paid to persons of reproductive/working age." In: UNECE/UNFPA, Generations and Gender Programme. Exploring Future Research and Data Collection Options. United Nations, Geneva: 59-104. 
Lesthaeghe, R., and van de Kaa, D., 1986. "Twee demografische transities?" In: Lesthaeghe, R., and van de Kaa, D. (eds), Groei of Krimp? Book volume of 'Mens en Maatschappij'. Van Loghum-Slaterus, Deventer: 9-24.

Neyer, G., 2003. "Gender and generations dimensions in welfare state policies." MPIDR Working Paper 2003-022. Max Planck Institute for Demographic Research, Rostock.

Prskawetz, A., Vikat, A., Philipov, D., and Engelhardt, H., 2003. "Pathways to stepfamily formation in Europe: Results from the FFS." Demographic Research 8: 107-149. Available http://www.demographic-research.org/volumes/vol8/5.

van de Kaa, D., 1987. "Europe's second demographic transition." Population Bulletin $42(1)$. 
Demographic Research - Special Collection 3: Article 1

-- Contemporary Research on European Fertility: Perspectives and Developments -- 